\title{
Aging And Health In South Dakota: Who Will Provide Care?
}

Diane K. Duin, (E-mail: Diane.Duin@usd.edu), University of South Dakota

DeVee Dykstra, (E-mail: DeVee.Dykstra@usd.edu), University of South Dakota

\begin{abstract}
Demographers have long been writing of an aging population. The forthcoming demographic changes predicted include the doubling of the elderly in selected states between 1995 and 2025, and the possibility that the numbers of people over age 85 is expected to reach at least 27 million by 2050. These changes in the population will have a major impact on many sectors of the United States economy, including health care. The effect on health care will include changes in technology to provide needed services to the elderly, access to medications by the elderly, overall service provision to the elderly by health care organizations, as well as reimbursement for services to the elderly. The most dramatic affect on health care is still a couple of decades away. As a result of the demographic trends there will be an insufficient supply of health care workers, while at the same time an increase in the health care needs of the elderly. In South Dakota the working population, those 16 to 64 years of age, is experiencing significant changes. The 16 to 44 year old segment of the population has declined by 10.4\%. The 45 to 64 year old segment has increased by 23.5\%. These changes in the South Dakota demographics indicate that the working population is aging, while the numbers of individuals available to replace them in the work force (the replacement group) is declining. The data provides an indication that there will be more elderly consuming greater amounts of health care resources and fewer health care professionals, specifically nurses, in South Dakota to provide health care for the elderly.
\end{abstract}

\section{INTRODUCTION}

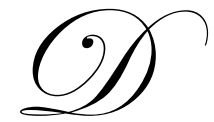

emographers have long been writing of an aging population. The forthcoming demographic changes predicted include the doubling of the elderly in selected states between 1995 and 2025 and the possibility that the numbers of people over age 85 is expected to reach at least 27 million by 2050 (Lanser, 2003). These changes in the population will have a major impact in many sectors of the United States economy, including health care.

The effect on health care will include changes in technology to provide needed services to the elderly, access to medications by the elderly, overall service provision to the elderly by health care organizations, as well as reimbursement for services to the elderly. But the most dramatic affect on health care is still a couple of decades away. "As a result of demographic trends in our country, we will face an insufficient supply of nurses, pharmacists, radiologists, and physicians, to name a few...the senior population uses health care services at a much higher level than the rest of the population..." (Lanser, 2003, p. 8). Who will be there to provide care as those numbers in the working segment of the population age?

\section{AGING TRENDS}

"In 1860, half the population of the United States was under age 20, and most of the population was not expected to live to age 65" (Hobbs and Damon, 1996, p. 2-1). According to the statistics of the 2000 Census there are $34,991,753$ or $12.4 \%$ of the American population over the age of 65 (U.S. Census, 2000). "According to the Census Bureau's middle series projections, half the population would be 37 or older in 2010 if levels of fertility, mortality, and net migration follow recent trends..." (Hobbs and Damon, 1996, p. 2-1). 
"In this century, the rate of growth of the elderly population (persons 65 years old and over) has greatly exceeded the growth rate of the population of the country as a whole" (Hobbs, 2001). In 1900 the number of those over the age of 65 years was 3,080,000 or 4.1\% of the total population (Administration on Aging). By 1950 those over the age of 65 comprised $8.1 \%$ of the total population at 12,269,000 (Administration on Aging). According to the U.S. Census for 2000 the total population of those over 65 was $34,991,753$ or $12.4 \%$ of the population (U.S. Census, 2000).

"Overall the oldest old are projected to be the fastest growing part of the elderly population into the next century" (Hobbs, 2001). Although many states are experiencing a change in demographics patterns, in South Dakota the aging trend is more evident. By 2025, over one-fifth of all residents in South Dakota will be 65 years old or older. In $2000,14.3 \%$ of South Dakota's total population was over the age of 65 which was a $1.1 \%$ from 1980 (Population for South Dakota). What is happening in South Dakota with respect to the aging of the population is happening in many other states.

Chart 1 - Older Population by Age

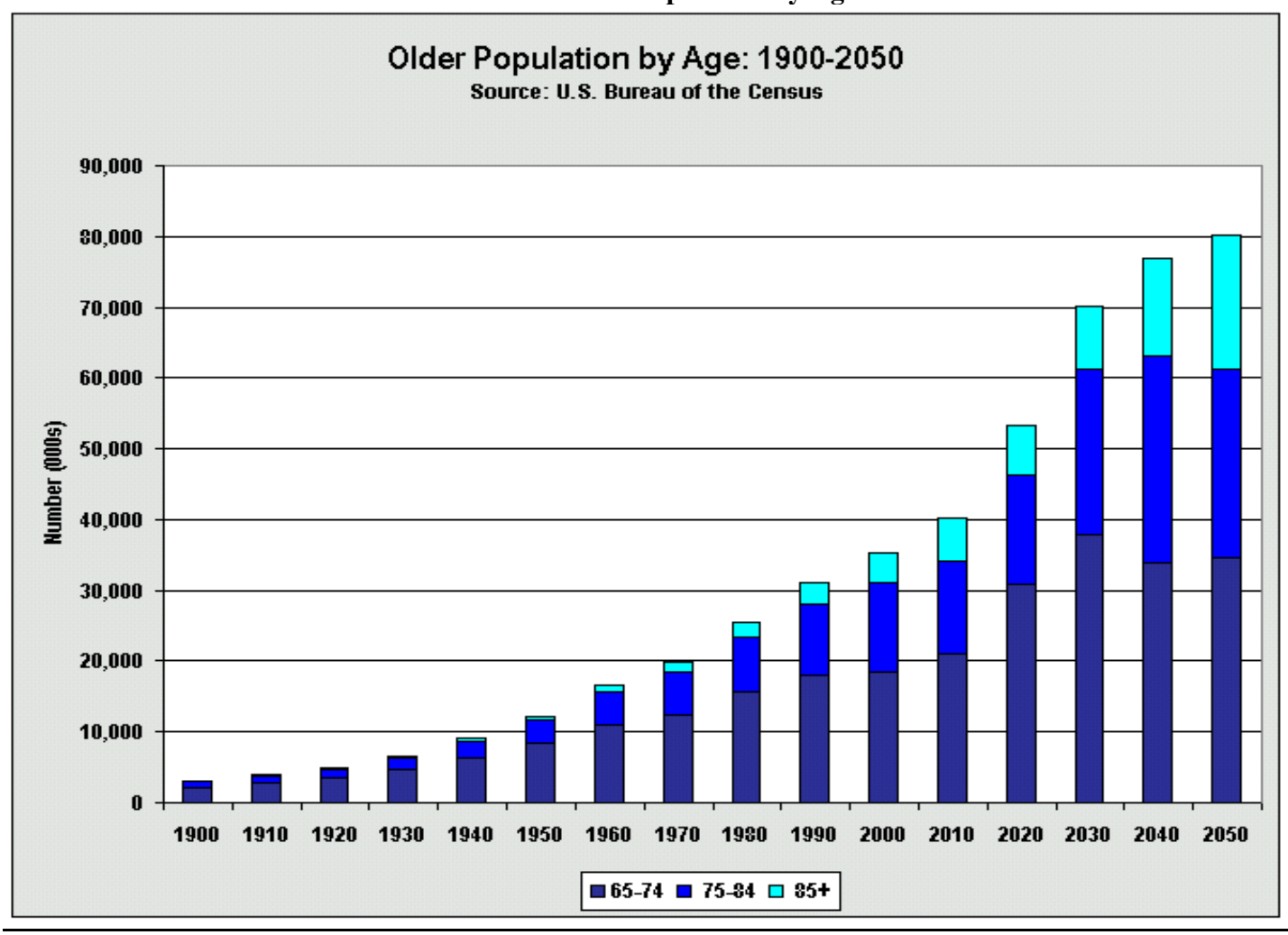

Source: Administration on Aging based on Census Bureau Data

\section{SOUTH DAKOTA POPULATION DEMOGRAPHICS}

The total population of the state of South Dakota in 1960 was 680, 514 of which 71, 205 were over the age of 65, and 4, 047 were over the age of 85. By 2000 the over 65 years segment of the population had increased to 135,257 or slightly over $47 \%$. For those over the age of 85 the increase was $74 \%$ from 4,407 in 1960 to 16,086 in 2000 (Population for South Dakota).

The greatest decrease in South Dakota's population between 1960 and 1980 was in the number of persons under the age of 16. The greatest increase in the population for selected years was $157.6 \%$ experienced in the 85 and 
older segment. The number of individuals in the categories between 20 years and 44 years grew, while the age 45 to 64 experienced a slight drop in number. For those between the ages of 65 and 84 there was an increase in population. (See Table 1.)

Table 1: South Dakota Population 1960 And 1980

\begin{tabular}{||c|c|c|c|c||}
\hline \hline Age Segment & $\mathbf{1 9 6 0}$ & $\mathbf{1 9 8 0}$ & $\begin{array}{c}\text { Change 1960 TO } \\
\mathbf{1 9 8 0}\end{array}$ & \% change \\
\hline \hline & & & $-60,845$ & $-25.3 \%$ \\
\hline 15 years and under & 239,845 & 178,333 & 15,070 & $36.6 \%$ \\
\hline 16 to 19 years & 41,225 & 56,295 & 27,288 & $69.7 \%$ \\
\hline 20 to 24 years & 39,165 & 66,453 & 10,573 & $6.7 \%$ \\
\hline 25 to 44 years & 158,657 & 169,230 & $-1,053$ & $-0.8 \%$ \\
\hline 45 to 64 years & 130,632 & 129,579 & 819 & $7.7 \%$ \\
\hline 65 to 66 years & 10,608 & 11,427 & 3,375 & $9.5 \%$ \\
\hline 67 to 74 years & 35,713 & 39,088 & 9,730 & $47.8 \%$ \\
\hline 75 to 84 years & 20,347 & 30,077 & 6,380 & $157.6 \%$ \\
\hline 85 years and over & 4,047 & 10,427 & 10,254 & $1.5 \%$ \\
\hline TOTAL & 680,514 & 690,768 & & \\
\hline
\end{tabular}

Source: U.S. Census Bureau, 2000

The greatest decrease in South Dakota's population between 1980 and 2000 was in the number of persons between the ages of 20 and 24. This is the same population (those 15 years and under) that had decreased from 1960 to 1980 . As in the 1960 to 1980 data the greatest increase in the population, at $54.3 \%$, between 1980 and 2000 was the 84 years and older segment. Except for the drop in population for the 65 to 66 year old ${ }^{1}$, all other age segments experienced an increase in numbers. (See Table 2.)

Table 2: South Dakota Population 1980 And 2000

\begin{tabular}{||c|c|c|c|c||}
\hline AGE SEGMENT & $\mathbf{1 9 8 0}$ & $\mathbf{2 0 0 0}$ & $\begin{array}{c}\text { Change 1980 TO } \\
\mathbf{2 0 0 0}\end{array}$ & \% Change \\
\hline \hline 15 years and under & 178,333 & 165,018 & $-13,315$ & $-7.4 \%$ \\
\hline 16 to 19 years & 56,295 & 62,463 & 6,168 & $10.9 \%$ \\
\hline 20 to 4 years & 66,453 & 52,802 & $-13,651$ & $-24.6 \%$ \\
\hline 25 to 44 years & 169,230 & 206,399 & 37,169 & $21.9 \%$ \\
\hline 45 to 64 years & 129,579 & 160,031 & 30,452 & -675 \\
\hline 65 to 66 years & 11,427 & 10,752 & 3,289 & $-5.9 \%$ \\
\hline 67 to 74 years & 39,088 & 42,377 & 8,839 & $8.4 \%$ \\
\hline 75 to 84 years & 30,077 & 38,916 & 5,659 & $29.3 \%$ \\
\hline 85 years and over & 10,427 & 16,086 & 64,076 & $54.3 \%$ \\
\hline TOTAL & 690,768 & 754,844 & & $9.3 \%$ \\
\hline
\end{tabular}

Source: U.S. Census Bureau, 2000

\section{DEPENDENCY RATIO}

The dependency ratio is an indicator of the economically dependent to productive portion of the population. The dependency ratio of a population represents the number or proportion of individuals in the dependent segment of the population divided by the number or proportion of individuals in the working population. Generally the dependent segments of a population are defined as those 15 years and under plus those 65 years and older. The working

\footnotetext{
${ }^{1}$ The drop in the 65 to 66 year old population is attributable to the decrease in births for the relevant years of 1934 and 1935 which occurred during the "dirty thirties" depression era.
} 
population is generally considered to be those 16 to 64 years of age. The old-age dependency ratio is the number or proportion of individuals 65 years of age and older divided by the number or proportion of individuals between the ages of 16 and 64, the working population.

The old-age dependency ratio for South Dakota over the past 30 years has continually increased from 19 in 1960, to 21 in 1980, and 22 in 2000. (See Table 3.)

Table 3: Old-Age Dependency Ratios For South Dakota

\begin{tabular}{||c|c|c|c||}
\hline & $\mathbf{1 9 6 0}$ & $\mathbf{1 9 8 0}$ & $\mathbf{2 0 0 0}$ \\
\hline \hline Old Age Dependency Ratio & 19 & 21 & 22 \\
\hline
\end{tabular}

When considering the working population of South Dakota, those 16 to 64 years of age, the segment of the population from 16 to 44 has declined by $10.4 \%$ over the past 20 years, while the 45 to 64 year old segment has increased by $23.5 \%$. In other words, those who are in the working population are also aging, while those who will replace them in the work place (16 to 44 years old) are declining. When consideration is given to those under 15 years of age, the two future decades of the working population in South Dakota, the decrease between 1980 and 2000 for that segment of the population was 13,315 or $7.4 \%$. (See Table 2.) Consequently, the dependency ratio for South Dakota will continue to grow with the aging population and declining working population.

Table 4: Selected Segments Of The South Dakota Population

\begin{tabular}{||l|c|c|c|}
\hline & $\mathbf{1 9 8 0}$ & $\mathbf{2 0 0 0}$ & \% Change \\
\hline \hline 16 to 44 years & 291,978 & 261,526 & $-10.4 \%$ \\
\hline 45 to 64 years & 129,579 & 160,031 & $23.5 \%$ \\
\hline
\end{tabular}

Source: U.S. Census, 2000

\section{SOUTH DAKOTA SELECTED HEALTH CARE WORKER DEMOGRAPHICS}

Who will be there to provide care to those who need it as the numbers in the working segment of the population age decrease? Data on the actual number of all health care workers in South Dakota is not aggregately collected by any single agency. Health care workers are typically counted by the agency which licenses them to practice in South Dakota. For example, doctors are licensed by the South Dakota Medical Association and nursing home administrators are licensed by the South Dakota Board of Nursing Home Administrators. If a particular segment of health care worker is not licensed data on the individuals serving in that health care occupation are not aggregately collected. Data for broad categories of health care workers is collected by the Equal Employment Opportunity Commission; however, the data is not segmented by age of the licensed worker.

One of the few health care workforce supply reports which have recently been published is the Report of Nursing Workforce Supply in South Dakota. "This report is based on findings of RN and LPN surveys returned with license renewal forms to the South Dakota Board of Nursing, which renews licenses every two years" (Hegge, 2002, p. 1). "There are 221 fewer LPNs than there were in the 1980s, but more than a $3 \%$ drop has been experienced in the last two years. Over half (60\%) of LPNs are over age 40" (Hegge, 2002, p. 15). According to the Report of Nursing Workforce Supply in South Dakota, “...20.6\% of LPNs work in hospitals" (p.15) which is a decrease from the reported $48.0 \%$ in the previous decade. "The largest employer of LPNs is now the long-term care industry, which employs $25.6 \%$ of LPNs" (Hegge, 2002, p. 15). 
Table 5: Age Comparison Of Lpns In The Nursing Workforce

\begin{tabular}{|c|c|c|c|c|c|c|c|c|}
\hline \multirow[t]{2}{*}{$\begin{array}{l}\text { AGE OF } \\
\text { LPNS IN } \\
\text { YEARS }\end{array}$} & \multicolumn{2}{|c|}{$\begin{array}{c}\text { 1994-96 } \\
\text { BIENNIUM }\end{array}$} & \multicolumn{2}{|c|}{$\begin{array}{c}1997-99 \\
\text { PREVIOUS } \\
\text { BIENNIUM }\end{array}$} & \multicolumn{2}{|c|}{$\begin{array}{c}2000-02 \\
\text { CURRENT BIENNIUM }\end{array}$} & \multicolumn{2}{|c|}{$\begin{array}{c}\text { CHANGE FROM } \\
\text { PREVIOUS } \\
\text { BIENNIUM TO } \\
\text { CURRENT BIENNIUM }\end{array}$} \\
\hline & $\#$ & $\%$ of total & $\#$ & $\%$ of total & $\#$ & $\%$ of total & \# & $\%$ \\
\hline $18-25$ & 67 & $2.9 \%$ & 69 & $3.1 \%$ & 54 & $2.5 \%$ & -15 & $-21.7 \%$ \\
\hline $26-35$ & 369 & $17.1 \%$ & 300 & $13.6 \%$ & 222 & $10.4 \%$ & -78 & $-26.0 \%$ \\
\hline $36-45$ & 848 & $36.7 \%$ & 765 & $36.2 \%$ & 623 & $29.2 \%$ & -172 & $-21.6 \%$ \\
\hline $46-55$ & - & - & - & - & 580 & $27.2 \%$ & - & - \\
\hline $56+$ & 279 & $12.1 \%$ & 335 & $15.2 \%$ & 356 & $16.7 \%$ & +21 & $+6.3 \%$ \\
\hline $\begin{array}{l}\text { Missing } \\
\text { Age* }\end{array}$ & 721 & $31.2 \%$ & 699 & $31.8 \%$ & 295 & $13.8 \%$ & - & - \\
\hline Totals & 2,311 & $100 \%$ & 2,198 & $100 \%$ & 2,130 & $100 \%$ & -68 & $-3.1 \%$ \\
\hline
\end{tabular}

Source: Report of Nursing Workforce Supply in South Dakota, June 2002

*Includes 45-55 age segment and those not reporting age for the Biennium.

"There has been a $1.73 \%$ decrease in actively licensed RNs in this biennium, with 45 fewer RNs working full-time and 226 fewer RNs working part-time" (Hegge, 2002, p. 38). Additionally, the Report of Nursing Workforce Supply in South Dakota indicates that "...since the previous decade, the proportion of RNs working in hospitals has dropped from $61 \%$ to $51.9 \%$... and a drop in the actual number of RNs working in long-term care from 1,121 to 981 " (p. 38).

Table 6: Age Comparison Of Rns In The Nursing Workforce

\begin{tabular}{||c|c|c|c|c|c|c|c|c||}
\hline \hline \multirow{3}{*}{$\begin{array}{c}\text { AGE OF } \\
\text { RNS IN } \\
\text { YEARS }\end{array}$} & \multicolumn{2}{|c|}{$\begin{array}{c}\text { 1994-96 } \\
\text { BIENNIUM }\end{array}$} & \multicolumn{2}{c|}{$\begin{array}{c}\text { 1997-99 } \\
\text { PREVIOUS } \\
\text { BIENNIUM }\end{array}$} & \multicolumn{2}{c|}{$\begin{array}{c}\text { 2000-02 } \\
\text { CURRENT BIENNIUM }\end{array}$} & $\begin{array}{c}\text { CHANGE FROM } \\
\text { TO CURRENT } \\
\text { BIENNIUM }\end{array}$ \\
\cline { 2 - 11 } & $\#$ & $\%$ of total & $\#$ & $\%$ of total & $\#$ & $\%$ of total & $\#$ & \# \\
\hline $18-25$ & 355 & $3.6 \%$ & 341 & $3.3 \%$ & 305 & $3.0 \%$ & -36 & $10.6 \%$ \\
\hline $26-35$ & 2,203 & $22.1 \%$ & 2,100 & $22.1 \%$ & 1,793 & $17.6 \%$ & -317 & $-15.0 \%$ \\
\hline $36-45$ & 3,596 & $36.0 \%$ & 3,722 & $20.4 \%$ & 3,293 & $32.3 \%$ & -429 & $-11.5 \%$ \\
\hline $46-55$ & 2,197 & $22.0 \%$ & 2,772 & $35.9 \%$ & 2,640 & $25.9 \%$ & -132 & $-4.8 \%$ \\
\hline $55+$ & 1,141 & $11.4 \%$ & 1,387 & $13.4 \%$ & 1,466 & $14.4 \%$ & +79 & $+5.7 \%$ \\
\hline $\begin{array}{c}\text { Missing } \\
\text { Age }\end{array}$ & 491 & $4.9 \%$ & 30 & $.3 \%$ & 686 & $6.7 \%$ & - & - \\
\hline Totals & $\mathbf{9 , 9 8 3}$ & $\mathbf{1 0 0 \%}$ & $\mathbf{1 0 , 3 6 2}$ & $\mathbf{1 0 0 \%}$ & $\mathbf{1 0 , 1 8 3}$ & $\mathbf{1 0 0 \%}$ & $\mathbf{- 1 7 9}$ & $\mathbf{- 1 . 7 3 \%}$ \\
\hline \hline
\end{tabular}

Source: Report of Nursing Workforce Supply in South Dakota, June 2002

As indicated by the Report of Nursing Workforce Supply in South Dakota the number of RNs and LPNs in South Dakota has declined. The RNs and LPNs have experienced aging of the workforce similar to the overall aging of the population.

\section{EDUCATION ATTAINMENT OF NURSES}

Increase in the number of LPNs and RNs begins with increasing student enrollment in those fields. According to Hegge, (2002) there was a $26 \%$ decline in the number of students enrolled in LPN programs of study and a $6.3 \%$ decline in enrollment of students in RN programs of study in South Dakota, between the 1997-1999 biennium and 2000-2002 biennium. According to Underwood (2005), nationally nursing schools had to turn away qualified applicants due to understaffing at those schools. Additionally, the authors' preliminary inquiry to South Dakota nursing programs of study indicated a lack of clinical opportunities. Opportunities for students in nursing 
programs to participate in experiences within health care facilities (referred to as clinicals) is a necessary prerequisite to expanding the number of students enrolled in nursing programs of study.

The lack of clinical opportunities appears to be the result of too few nurses with the necessary educational credentials to supervisor the student nurses while in the health care facility. In South Dakota, during the 2000-2002 biennium, only four (4) LPNS held a bachelor's degree in nursing and none reported holding a master's degree (Hegge, 2002). However, there has been an increase in the number of South Dakota licensed RNs with master's and doctorate degree in nursing. The major issue is the geographic locations of the advanced degreed RNs.

In South Dakota there are "magnet" counties, those counties which attract a disproportionate share of the population. RNs with doctorate degrees are very heavily located in four counties of South Dakota, two of which have a university and the other two are in the state's two metropolitan areas. In general, opportunities for clinicals are, therefore, limited.

\section{PROJECTIONS FOR SOUTH DAKOTA}

Will there be health care workers available to care for the elderly? In order to answer that question much more refined data on health care workers will need to be collected and analyzed. However, with respect to the health care occupations of RN and LPN in South Dakota consideration must be given to what is termed the replacement group, those LPNs and RNs under the age of 45.

Almost 50\% of the RNs in South Dakota are over the age of 45. These are the individuals will most likely consider retirement from the profession within the next 20 years. The under 15 years of age population for South Dakota continues to decrease. This is the segment of the population who will potentially be entering the workforce in the next two decades. The decrease in the available upcoming workforce and the aging of the currently licensed RNs will leave a gap in the number of available nursing caregivers for the increasingly elderly population in South Dakota. LPNs who are over the age of 45 account for $51 \%$ of the profession. The replacement group for those LPNs is also shrinking as is indicated by the trending data in the Report of Nursing Workforce Supply in South Dakota.

Table 7 - Age Of Rns And Lpns By Selected Category For Current Biennium

\begin{tabular}{|c|c|c|c||}
\hline & $\mathbf{1 8 - 4 5}$ years & 46+ Years & $\begin{array}{c}\text { \% of total who are 46+ } \\
\text { years }\end{array}$ \\
\hline \hline RN & 5,391 & 4,792 & $47 \%$ \\
\hline LPN & 899 & 936 & $51 \%$ \\
\hline
\end{tabular}

Source: Report of Nursing Workforce Supply in South Dakota, June 2002

\section{CONCLUSION}

All indications are a greater need for LPNs and RNs in the long-term care setting due to the aging of the population. A cursory review of the limited available data provides an indication that there will be more elderly consuming greater amounts of health care resources and fewer nursing professionals to care for them. This holds true for South Dakota, as well as throughout the United States. Preliminary analysis indicates the need to attract current RNs and LPNs into long-term care, as well as the need to increase the number of educational opportunities for individuals desiring to enter the nursing occupation.

Much needs to be done before definitive answers can be given to who will care for the persons of South Dakota. Even so, recommendations can be provided at this early stage. For example, an increase in the number of nursing master's degree recipients is necessary to provide sufficient clinical opportunities to nursing students. There is a two decade window of opportunity to start addressing the long-term care issue before the very real crisis hits. The process of educating the educators needs to begin now. 


\section{REFERENCES}

1. Administration on Aging. Older Population by Age 1900-2050. Retrieved February 2003 from http://www.aoa.gov/aoa/stats/AgePop2050Chart-numbers.html.

2. Hegge, M. and the South Dakota Consortium for Nursing Workforce Development: Colleagues in Caring Project (2002). Report of Nursing Workforce Supply in South Dakota. Sioux Falls, SD: SD Consortium.

3. Hobbs, Frank (2001). The Elderly Population. Retrieved March 3, 2003, from

http://landview.census.gov/population/www/pop-profile/elderpop.html

4. Hobbs, Frank B. and Damon, Bonnie L. (1996). 65+ in the United States. U.S. Census Special Reports.

5. Lanser, Ellen G. (2002). Our Aging Population. Healthcare Executive, 18(1), 7-11.

6. Population for South Dakota and Counties for Selected Age Groups 1970 - 1990 (2000). Compiled by South Dakota Data Center, Vermillion, South Dakota from the U.S. Census Bureau Report.

7. United States Census (2000). Retrieved May 9, 2003, from http://www.census.gov.

8. Underwood, A. (2005). Diagnosis: Not enough nurses. Newsweek, 146(24), 80.

\section{NOTES}


NOTES 